\title{
Analysis of silicon concentration periodicity for the past 2.4 Ma in sediments from Lake Baikal site BDP 96-2
}

\author{
R. Dawson ${ }^{1,2, *}$, R. Wei $^{2}$, S. Tao ${ }^{2}$, Y. Ito ${ }^{3}$, K. Yamanaka ${ }^{3}$, H. Haraguchi ${ }^{3}$ \\ ${ }^{1}$ School of Environment and Natural Resources, China Agricultural University, Beijing 100094, PR China \\ ${ }^{2}$ Department of Urban and Environmental Science, Peking University, Beijing 100871, PR China \\ ${ }^{3}$ Department of Applied Chemistry, Graduate School of Engineering, Nagoya University, Furo-cho, Chikusa-ku, \\ Nagoya 464-8603, Japan
}

\begin{abstract}
The current study examines the potential cyclical nature of the elemental concentration record of silicon in sediments from Lake Baikal site BDP 96-2 in an attempt to clarify trends in periodicity observed for periods from $700 \mathrm{kyr} B P$ to the present, $760 \mathrm{kyr} \mathrm{BP}$ to $1.43 \mathrm{Ma}$, and 1.47 to 2.4 Ma. The results indicate the presence of the $100 \mathrm{kyr}$ cycle during the past $700000 \mathrm{yr}$, as identified in other research. They also indicate the presence of a strong 74 kyr cycle from $760 \mathrm{kyr}$ BP to $1.43 \mathrm{Ma}$, with a weaker $44 \mathrm{kyr}$ cycle. For the period from 1.47 to $2.4 \mathrm{Ma}$, we observed evidence of strong 465 and 155 kyr cycles, in addition to a moderate 93 kyr cycle and various lesser cycles. This new evidence represents one of the first findings of longer cycles, as predicted by classic insolation theory, and sheds some initial light on Imbrie's 400 kyr question.
\end{abstract}

KEY WORDS: Silicon concentration · Climate change $\cdot$ Paleoenvironment $\cdot$ Milankovitch $\cdot$ Lake Baikal · Sediments

\section{INTRODUCTION}

In general, it is considered that sediments from lakes, ponds, harbors and rivers are important indicators of environmental change. The results of an earlier study of sediments in Lake Biwa, Japan, by Horie (1988) reported that paleoclimatic variations reconstructed from pollen analysis showed signs of response to the insolation variations as predicted by classic Milankovitch Climate Cycle theory, in which glacial-interglacial cycles are driven by variations in the Earth's orbital parameters (eccentricity, obliquity and precession). Other authors using biogenic silica (bioSi) preserved in sediments as a proxy for paleoclimate change have found evidence of classic 100, 41, 23, and 19 kyr Milankovitch cycles, with the 100 kyr cycle dominant during the past million years (Colman et al. 1995, Williams et al. 1997, Phedorin et al. 2000). The 100 kyr cycle during the last million years has also been shown to be dominant in the study of sea-ice volumes through $\delta^{18} \mathrm{O}$ analysis (Imbrie et al. 1993). Unpublished research from our investigation of the silicon ( $\mathrm{Si}$ ) concentration profile in Lake Baikal site BDP 93-2 sediments (collected 5 to $6 \mathrm{~km}$ offshore from the Buguldeika site $\left[52^{\circ} 30^{\prime} \mathrm{N}, 106^{\circ} 15^{\prime} \mathrm{E}\right]$ and opposite the mouth of the Selenge River in the northern part of the lake's southern basin) indicated the presence of some classic Milankovitch cycles during the past $500000 \mathrm{yr}$, particularly the 41 and 100 kyr cycles, with the $41 \mathrm{kyr}$ cycle being clearly dominant. Because those results were at odds with existing research from other Lake Baikal boring cores, in which the 100 kyr cycle seemed dominant during the past million years (Colman et al. 1995, Williams et al. 1997, Phedorin et al. 2000), we chose to examine the record for site BDP 96-2, where the geography is significantly different from the earlier BDP 93-2 site. 
Lake Baikal consists of 3 major basins, with a separating ridge (Academician Ridge) between the northern and central basins and a saddle (Buguldeika Saddle) between the central and southern basins. Several long sediment cores have been collected as part of the Baikal Drilling Project (BDP) during the past decade. In 1996, 2 cores, BDP 96-1 (200 m) and 96-2 (100 m), were collected at Academician Ridge in the central basin. Academician Ridge is a relatively stable environment. Unlike the Buguldeika sampling site, where the BDP 93-2 samples were taken, the sediments at Academician Ridge are far less influenced by river inflows, thus reflecting more influence from biogenic and aquatic sources. The Buguldeika sampling site, on the other hand, is a saddle on the northern end of the southern basin and only a few kilometers from the west shore of the lake. The sediments there are undoubtedly affected by inflow from the Buguldeika River just to the south of the site, as well as tectonic lift. In addition, the Selenga River, which provides more than half of the total water entering Lake Baikal, is located to the east of the Buguldeika sampling site. The Selenga River flows northward into Baikal, representing a major drainage basin for the Mongolian Steppe to the south. As such, the sediment record in Lake Baikal's southern basin reflects quite strongly the circulation and mixing effects dependent on climate and weather regimes for a geography quite different from those influencing the central and more northern reaches of the lake that may have been under more direct influence from glaciation.

In this study we examine the Si record in sediments from site BDP 96-2 (411 samples) for indications of periodicity as predicted by Milankovitch insolation theory. The sedimentation rate for site BDP 96-2 $\left(53^{\circ} 41^{\prime} 49^{\prime \prime} \mathrm{N}, 108^{\circ} 21^{\prime} 06^{\prime \prime} \mathrm{E}\right)$ has been estimated at $4 \mathrm{~cm} \mathrm{kyr}^{-1}$, thus offering a potential climate record for the past 2.4 Ma (Baikal Drilling Project BDP 96 [Leg II]

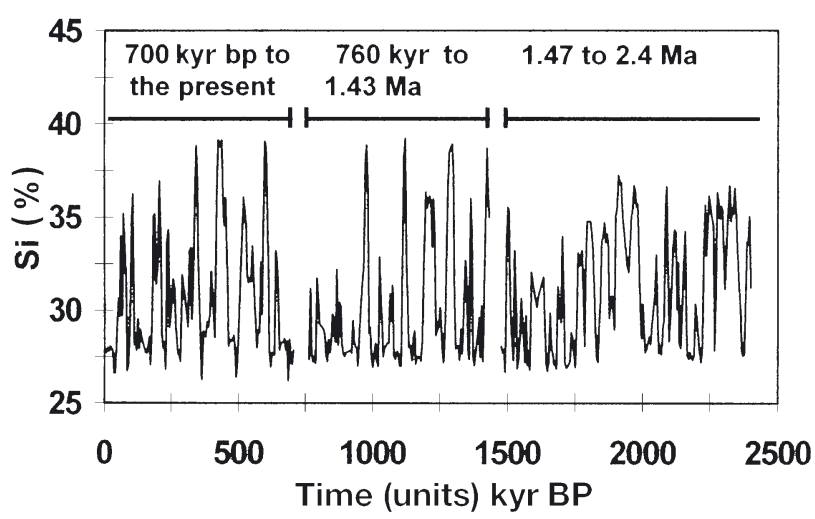

Fig. 1. Adjusted concentration profile of Si for site BDP 96-2 for the past 2.4 Ma showing 3 periods: $700 \mathrm{kyr}$ BP to present; $760 \mathrm{kyr} B \mathrm{BP}$ to $1.43 \mathrm{Ma}$; 1.47 to $2.4 \mathrm{Ma}$
Members 1997). Because site BDP 96-2 is geographically quite different from other sites in Lake Baikal, the results may offer further insight into questions concerning high-latitude continental interior paleoclimatic change and the degree to which the sediment record at Lake Baikal supports classic Milankovitch insolation theory.

\section{METHODOLOGY}

In the earlier studies ICP-MS/ICP-AES (inductively coupled plasma-mass spectrometry/inductively coupled-plasma atomic emission spectrometry) were used to analyze elements in the BDP 93-2 sediment core with good reliability and reproducibility in analytical results (Wei et al. 1997, 1999). It takes a significant amount of time, however, to digest sediments into solutions by alkali fusion and analyze the results by ICPMS/ICP-AES. Since large numbers of samples are involved in this study at site BDP 96-2, X-ray fluorescence spectrometry (XRF) was used to analyze the $\mathrm{Si}$ content of the sediments. The advantages of XRF in analyzing elemental content are that (1) the sediments can be analyzed in solid form and do not need to be digested in solutions, and (2) multiple elements can be analyzed simultaneously in each sample without losing accuracy (Yamanaka 2000).

Following chemical analysis by XRF, the concentration profile of $\mathrm{Si}$ was then examined for periodicity using spectral analysis. Spectral analysis has proven useful when searching for periodic patterns involved in time series data. Spectral density was computed by interpolating the data to equally spaced points, removing the average (but not the trend), equally weighting all points, and then taking the square of the Fourier transform. The spectrum was then normalized to unit mean.

The overall concentration profile for $\mathrm{Si}$ obtained from BDP 96-2 sediments for past 2.4 Ma is shown in Fig. 1. The profile shows that the $\mathrm{Si}$ concentration varied considerably from 26 to $39 \%$ throughout the period. Included in these variations, however, are 2 relatively large gaps in the data: one between ca. 700 and 760 kyr BP (29.55 to $31.98 \mathrm{~m}$ ) and the other between ca. 1.43 and 1.47 Ma (60.20 to $61.86 \mathrm{~m}$ ). Given these gaps, we chose to divide the samples into 3 sections: $700 \mathrm{kyr} \mathrm{BP}$ to the present, $760 \mathrm{kyr} \mathrm{BP}$ to $1.43 \mathrm{Ma}$, and 1.47 to $2.4 \mathrm{Ma}$, assuming a constant sedimentation rate. We then tested for periodicity based on the sample record, rather than attempting to fill in the missing gaps. Once complete, a time series dataset at $20 \mathrm{~cm}$ intervals was developed for profiling (474 data points), providing a $5000 \mathrm{yr}$ resolution for the Si profile. This division facilitated our interest in examining specific 
periods within the overall sediment record with a specific interest in any patterns in the unclear period between 1 and 1.4 Ma, as indicated by Muller \& Gordon (1997).

\section{RESULTS AND DISCUSSION}

\subsection{Silicon periodicity from $700 \mathrm{kyr} B P$ to the present}

The power spectrum of the Si profile from 700 kyr BP to the present is shown in Fig. 2, with frequency expressed in units of cycles per $20 \mathrm{~cm}$. A number of clear peaks can be observed corresponding to frequencies $(f)$ equal to $0.0479,0.1164,0.1781,0.2188$ and 0.2802 . The frequencies in the spectrum were converted to periodicities $(T)$ using the following equation developed by Wei (1999):

$$
T(\mathrm{kyr})=[700(\mathrm{kyr}) / 146] \times(1 / f)
$$

where $700 \mathrm{kyr}$ represents the time band and 146 the number of data points for the $700 \mathrm{kyr}$ period. Consequently, the resulting periodicities correspond to cycles of 100 ( $f: 0.0479), 41$ ( $f: 0.1164), 27$ ( $f: 0.1781)$, 22 ( $f: 0.2188)$ and $17 \mathrm{kyr}(f: 0.2802)$, which are fairly close to the periodicities predicted by Milankovitch's 3 periods of insolation: eccentricity (100 kyr), obliquity (41 kyr), and precession (23 and 19 kyr) (Berger et al. 1982).

It is generally suggested that glacial-interglacial cycles have occurred at a ca. 100 kyr rhythm during the past million years. Of the observed Si periodicities for last $700 \mathrm{kyr}$ in the analysis of BDP 96-2 sediments, the 100 kyr cycle was clearly the strongest (highest spectral density), although there was little difficulty

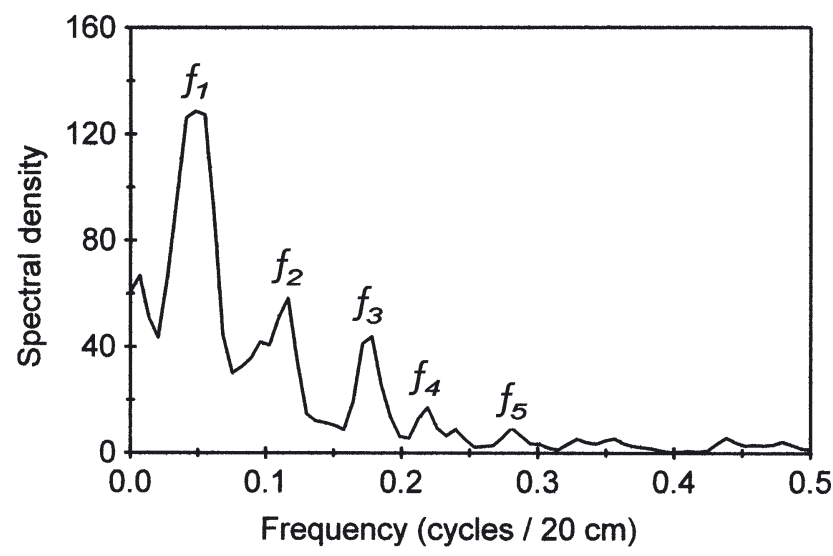

Fig. 2. Spectral analysis of Si concentration profile of the last $700 \mathrm{kyr}$ for site BDP 96-2, showing $f_{1}$ : 0.0479 (100 kyr); $f_{2}$ : 0.1164 (41 kyr); $f_{3}: 0.1781(27 \mathrm{kyr})_{;} f_{4}: 0.2188$ (22 kyr); $f_{5}: 0.2802(17 \mathrm{kyr})$ detecting other lesser cycles. The 100 kyr signal present in the results is similar to results obtained in other research for the past million years or so (Colman et al. 1995, Williams et al. 1997, Phedorin et al. 2000). In a study of Baikal sediments by Colman et al. (1995), there was a dominant 100 kyr cycle with a moderate 23 kyr cycle, and a relatively weak 41 kyr cycle. Phedorin et al. (2000) found a strong 100 kyr cycle with approximately equal 41 and 23 kyr cycles visible. Our findings, based on Si composition, suggest a dominant 100 kyr cycle with a moderate 41 kyr cycle (half the 100 kyr cycle's density), followed by a weakly moderate 27 kyr cycle (half the 41 kyr cycle's density) for last 700 kyr. The 27 kyr cycle is somewhat longer than that predicted in traditional theory and may be the result of sensitivity in the sediment record to both biogenic and terrigenous Si inputs or yet unknown interactions. We also detected weak, yet noticeable, 22 and $17 \mathrm{kyr}$ cycles, which correspond more closely with those predicted in classic insolation theory.

\subsection{Silicon periodicity from $760 \mathrm{kyr}$ BP to $1.43 \mathrm{Ma}$}

To further explore the possible nonlinear $100 \mathrm{kyr}$ cycle and the possible $1 \mathrm{Ma}$ boundary for its beginning, as suggested in other research (Muller \& Gordon 1997), we examined the Si record for the period from $760 \mathrm{kyr}$ BP to $1.43 \mathrm{Ma}$ (138 samples). The spectral analysis results are shown in Fig. 3. One dominant peak and 2 lesser peaks can be observed corresponding to frequencies equal to $0.0652,0.0217$ and 0.1087 . The frequencies were then converted to periodicities using the following equation (Wei 1999):

$$
T(\mathrm{kyr})=[670(\mathrm{kyr}) / 138] \times(1 / f)
$$

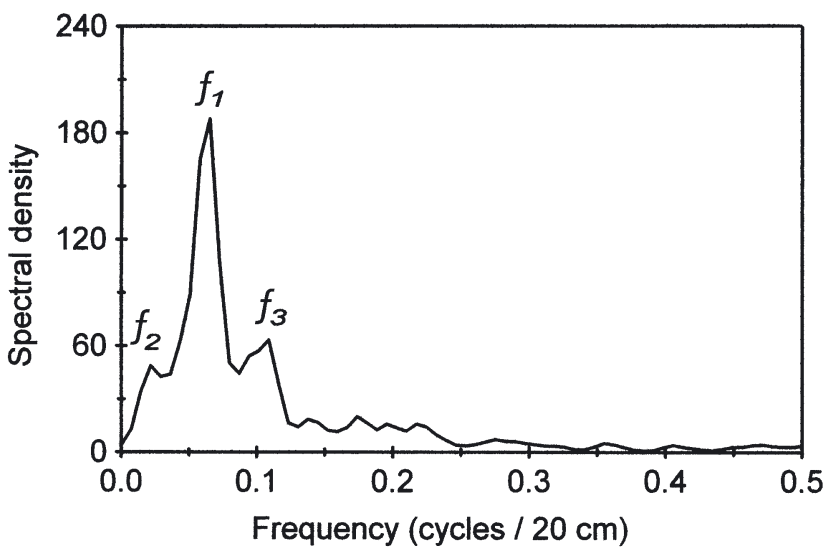

Fig. 3. Spectral analysis of $\mathrm{Si}$ concentration profile from $760 \mathrm{kyr}$ BP to $1.43 \mathrm{Ma}$ for site BDP $96-2$, showing $f_{1}$ : 0.0652 (74 kyr); $f_{2}: 0.0217$ (223 kyr); $f_{3}: 0.1087$ (44 kyr) 


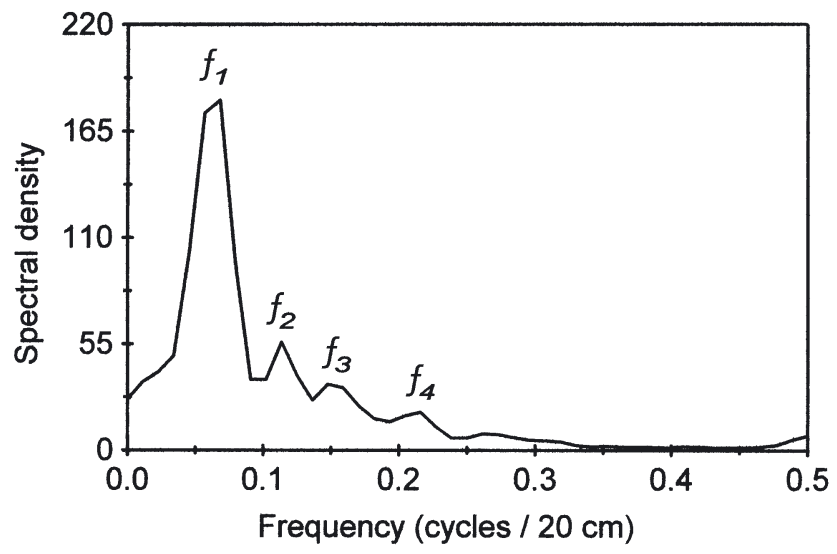

Fig. 4. Spectral analysis of Si concentration profile of 1.43 to 1.0 Ma for site BDP $96-2$, showing $f_{1}: 0.0682(70 \mathrm{kyr}) ; f_{2}$ : 0.1136 (42 kyr); $f_{3}: 0.1478$ (32 kyr); $f_{4}: 0.2159$ (22 kyr)

where 670 kyr represents the time band and 138 the number of data points for the period from $760 \mathrm{kyr}$ BP to $1.43 \mathrm{Ma}$. The resulting periodicities correspond to cycles of 74 ( $f: 0.0652), 223(f: 0.0217)$ and $44 \operatorname{kyr}(f$ : 0.1087 ). The 74 kyr cycle was clearly the strongest in spectral density, with the 2 lesser peaks at 223 and 44 kyr visible, but at approximately one-third the density of the 74 kyr peak.

Since the sampling period crosses the differentiating 1 Ma boundary suggested for the change to the dominant $100 \mathrm{kyr}$ cycle, we also analyzed the Si profile from 1.0 to $1.43 \mathrm{Ma}$ (88 samples) separately to see whether the results differed from those obtained for the period from $760 \mathrm{kyr}$ BP to $1.43 \mathrm{Ma}$ (Fig. 4). Although the sample size is relatively small, the results are interesting. Several peaks at frequencies of 0.0682 (70 kyr), 0.1136 (42 kyr), 0.1478 (32 kyr), and 0.2159 (22 kyr) can be identified. The strong 70 kyr cycle occurs in conjunction with a weak 42 kyr cycle (one-third the intensity of the 70 kyr peak) and much weaker 32 and 22 kyr cycles. As suggested by Parley \& Patterson (1995) and Muller \& Gordon (1997), the transition zone controlling conditions for the 100 kyr cycle could be the sudden accretion of interplanetary dust beginning approximately $1 \mathrm{Ma}$ ago. While the $41 \mathrm{kyr}$ cycle is thought to have been dominant from 1.5 to $2.5 \mathrm{Ma}$, it is believed that after the dust encounter stronger inclination effects leading to the $100 \mathrm{kyr}$ cycle obscured the 41 kyr cycle. On the basis of highresolution bioSi findings at site BDP 962, Williams et al. (1997) reported that the 41 kyr obliquity band became dominant from 0.8 to $1.8 \mathrm{Ma}$, with a shift to the 100 kyr eccentricity band during the past 0.8 Ma. Our results for site BDP 96-2 support the increasing influence of the $100 \mathrm{kyr}$ cycle over the past million years as discovered in other research. We did not find a strong 41 kyr cycle, however, in the period from 760 kyr BP to $1.43 \mathrm{Ma}$, nor from 1.0 to $1.43 \mathrm{Ma}$. What we did find was a relatively strong mid-70 kyr cycle during this transition period, with the inclusion of a weaker 44/42 kyr cycle. We believe our findings are somewhat in between those suggested in previous research, but with a probable tendency toward the results of Muller \& Gordon (1997), where the period from 1.0 to 1.5 Ma is not clearly defined relative to the dominance of the 100 or 41 kyr cycles.

\subsection{Silicon periodicity from 1.47 to $2.4 \mathrm{Ma}$}

Sediment samples from 1.47 to 2.4 Ma (190 samples) showed marked concentration variations in the Si profile, with an average concentration (31.10\%) higher than that of the entire Si profile $(30.68 \%)$. Results of the spectral analysis for this period are provided in Fig. 5. A number of clear peaks can be observed corresponding to frequencies of $0.0105,0.0316,0.0526$, $0.0842,0.1263$ and 0.2158 . The frequencies in the spectrum were again converted to periodicities using the form of equation developed earlier (Wei 1999):

$$
T(\mathrm{kyr})=[930(\mathrm{kyr}) / 190] \times(1 / f)
$$

where 930 kyr represents the time band and 190 the number of data points for the period between 1.47 and $2.4 \mathrm{Ma}$. The resulting periodicities corresponded to cycles of $465 \operatorname{kyr}(f: 0.0105), 155 \operatorname{kyr}(f: 0.0316), 93 \mathrm{kyr}$ $(f: 0.0526), 58 \operatorname{kyr}(f: 0.0842), 39 \operatorname{kyr}(f: 0.1263)$ and $23 \operatorname{kyr}(f: 0.2158)$, respectively.

Fig. 5 shows 2 fairly strong peaks in spectral density: one associated with a $465 \mathrm{kyr}$ cycle and the other with a 155 kyr cycle. Four lesser peaks are also visible at 93, 58, 39, $23 \mathrm{kyr}$, with spectral densities less than half those for the longer cycles. The presence of the $465 \mathrm{kyr}$

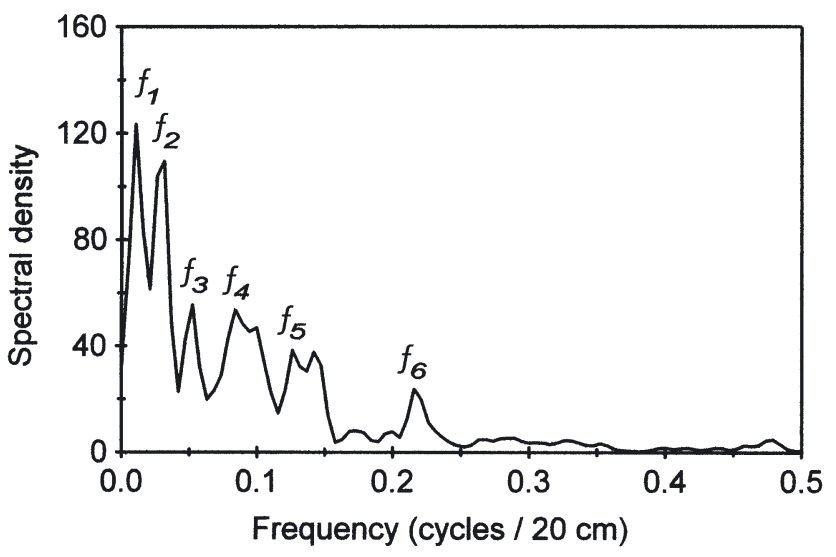

Fig. 5. Spectral analysis of Si concentration profile of 1.47 to 2.4 Ma for site BDP 96-2, showing $f_{1}: 0.0105$ (465 kyr); $f_{2}$ : 0.0316 (155 kyr); $f_{3}: 0.0526$ (93 kyr); $f_{4}: 0.0842$ (58 kyr); $f_{5}: 0.1263(39 \mathrm{kyr}) ; f_{6}: 0.2158(23 \mathrm{kyr})$ 
peak is interesting. One of the problems identified in research on $\delta^{18} \mathrm{O}$ ratios from deep-sea sediments has been the absence of a strong 400+ kyr cycle as predicted by insolation models (Imbrie's so-called $400 \mathrm{kyr}$ problem; Imbrie \& Imbrie 1980). While there is still no evidence of the 'triplet' (400, 125 and 95 kyr cycles) as predicted in classic insolation theory, there is some evidence for the much longer cycles in the older sediments of BDP 96-2 from 1.47 to 2.4 Ma and the issue should be explored further. One possible cause of masking of long-term evidence could be the influence of latitude (Baikal is a high-latitude continental interior lake) on the periodicity of insolation evidence, where the effects of precession become more dominant with increasing latitude (movement from the equator toward the poles). There is also a need to consider the effects of obliquity on equatorial insolation and the degree to which such changes affect Hadley Cells and the periodicity of the Caspian high-pressure regimen.

\section{CONCLUSION}

Previous research at Lake Baikal using bioSi concentrations found some evidence for a strong $100 \mathrm{kyr}$ cycle during the past million years, with the possibility of a $41 \mathrm{kyr}$ cycle dominating from 0.8 to $1.8 \mathrm{Ma}$ (Williams et al. 1997). Our research at site BDP 96-2 using an elemental profile of $\mathrm{Si}$ concentration approximates those findings within the past $700 \mathrm{kyr}$. However, our results for the periods prior to $700 \mathrm{kyr}$ BP are at odds with other findings at the site based on bioSi analysis. Our findings are similar to findings predicted in insolation theory and currently found in results of $\delta^{18} \mathrm{O}$ analysis from deep-sea sediments. Evidence of a strong $400+$ kyr cycle from the period prior to 1.47 Ma was unexpected and will require further investigation.

Certainly the use of proxy evidence, such as that obtained from sediment samples, is far from perfect, given the necessary assumptions needed to make the corresponding shift from depth to time scales. For the recent epoch of the last million years or so, there seems to be fairly consistent evidence of a strong 100 kyr cycle as supported by results from our investigations. What remains uncertain is the degree to which these records serve as evidence of periodicity in ice ages through changes in global ice volumes or whether they measure periodicity in terms of climate change without clear evidence relating to the periodicity of ice volumes.

Because of Lake Baikal's unique position as a highlatitude continental interior lake it may be possible to identify 2 different signals in the $\mathrm{Si}$ depositional record: one from biogenic sources, and the other from terrigenous sources. We hope that by further examining the broader elemental records from both BDP 93-2 and 96-2, the biogenic terrigenous dichotomy can be better clarified. In doing so, it may be possible to draw closer to an understanding of the relationship between climate change as predicted by insolation theory and the onset of ice ages as evidenced in $\delta^{18} \mathrm{O}$ records from deep-sea sediments.

\section{LITERATURE CITED}

Baikal Drilling Project BDP 96 (Leg II) Members (1997) Continuous paleoclimate record recovered for last 5 million years. EOS 78(51):597-604

Berger A, Imbrie J, Hays J, Kukla G, Saltzman B (1982) Milankovitch and climate. Proceedings of the NATO Advanced Research Workshop, Palisades, New York, USA, November 39-December 4, 1982

Colman SM, Peck JA, Karabanov EB, Carter SJ, Bradbury JP, King JW, Williams DF (1995) Continental climate response to orbital forcing from biogenic silica records in Lake Baikal. Nature 378:769-771

Horie S (ed) (1988) 1,400-m sedimentary record of paleoenvironment changes in the Lake Biwa. Douhousya, Kyoto (in Japanese)

Imbrie J, Imbrie JZ (1980) Model the climate response to orbital variation. Science 207:943-953

Imbrie J, Berger A, Boyle EA, Clemens SC and 15 others (1993) On the structure and origin of major glaciation cycles. 2. The 100,000-year cycle. Paleoceanography 8: 699-735

Muller RA, Gordon JM (1997) Glacial cycles and astronomical forcing. Science 277:215-218

Parley KA, Patterson DB (1995) A 100-kyr periodicity in the flux of extraterrestrial ${ }^{3} \mathrm{He}$ to the sea floor. Nature 378 : 600-603

Phedorin MA, Goldberg EL, Grachev MA, Levina OL, Khlystov OM, Dolbnya IP (2000) The comparison of the sediments of Lake Baikal as proxies of changing paleoclimates of the last 480 kyr. Nuclear Instr Methods Physics Res A 448:400-406

Wei R (1999) Multielement profiling analysis of Lake Baikal core sediments for elucidation of paleoenvironmental changes. PhD thesis, Nagoya University, Nagoya (in Japanese)

Wei R, Sawatari H, Haraguchi H (1997) Multielement profiling analysis of Lake Baikal boring core sediment samples for elucidation of paleo-environment. Anal Sci 13(Suppl): $419-420$

Wei R, Ikeda K, Takeuchi A, Jomen K, Yamanaka K, Sawatari H, Haraguchi H (1999) Multielemental determination of major-to-ultratrace elements in lake sediment reference materials by ICP-AES and ICP-MS. Bunseki Kagaku 48(3): 365-375 (in Japanese)

Williams DF, Peck J, Karabanov EB, Prokopenko AA, Kravchinsky V, King J, Kuzmin MI (1997) Lake Baikal record of continental climate response to orbital insolation during the past 5 million years. Science 278:1114-1117

Yamanaka K (2000) Use of XRF in studying paleoenvironmental change in Lake Baikal BDP 96 core sediments. MS thesis, Nagoya University, Nagoya (in Japanese)

Submitted: November 6, 2003; Accepted: April 6, 2004

Proofs received from author(s): May 21, 2004 